\title{
ERG deregulation induces IGF-1R expression in prostate cancer cells and affects sensitivity to anti-IGF-1R agents
}

\author{
Caterina Mancarella ${ }^{1}$, Irene Casanova-Salas ${ }^{2}$, Ana Calatrava ${ }^{3}$, Selena Ventura ${ }^{1}$, \\ Cecilia Garofalo ${ }^{1}$, José Rubio-Briones ${ }^{4}$, Vera Magistroni ${ }^{5}$, Maria Cristina Manara ${ }^{1}$, \\ José Antonio López-Guerrero ${ }^{2,}{ }^{*}$, Katia Scotlandi ${ }^{1, *}$ \\ ${ }^{1}$ CRS Development of Biomolecular Therapies, Experimental Oncology Lab, Rizzoli Orthopaedic Institute, Bologna, Italy \\ ${ }^{2}$ Laboratory of Molecular Biology, Fundación Instituto Valenciano de Oncología, Valencia, Spain \\ ${ }^{3}$ Department of Pathology, Fundación Instituto Valenciano de Oncología, Valencia, Spain \\ ${ }^{4}$ Department of Urology, Fundación Instituto Valenciano de Oncología, Valencia, Spain \\ ${ }^{5}$ Department of Health Sciences, University of Milano-Bicocca, Monza, Italy \\ *These authors have shared senior authorship \\ Correspondence to: \\ Katia Scotlandi, e-mail: katia.scotlandi@ior.it \\ Keywords: insulin-like growth factor receptor 1, prostate cancer, ETS fusion genes, anti-IGF-1R agents \\ Received: November 04, 2014 \\ Accepted: February 23, 2015 \\ Published: March 27, 2015
}

\section{ABSTRACT}

Identifying patients who may benefit from targeted therapy is an urgent clinical issue in prostate cancer ( $\mathrm{PCa}$ ). We investigated the molecular relationship between TMPRSS2-ERG (T2E) fusion gene and insulin-like growth factor receptor (IGF-1R) to optimize the use of IGF-1R inhibitors.

IGF-1R was analyzed in cell lines and in radical prostatectomy specimens in relation to T2E status. ERG binding to IGF-1R promoter was evaluated by chromatin immunoprecipitation (ChIP). Sensitivity to anti-IGF-1R agents was evaluated alone or in combination with anti-androgen abiraterone acetate in vitro at basal levels or upon ERG modulation.

IGF-1R analysis performed in PCa cells or clinical samples showed that T2E expression correlated with higher IGF-1R expression at mRNA and protein levels. Genetic modulation of ERG directly affected IGF-1R protein levels in vitro. ChIP analysis showed that ERG binds IGF-1R promoter and that promoter occupancy is higher in T2E-positive cells. IGF-1R inhibition was more effective in cell lines expressing the fusion gene and combination of IGF-1R inhibitors with abiraterone acetate produced synergistic effects in T2E-expressing cells.

Here, we provide the rationale for use of T2E fusion gene to select PCa patients for anti-IGF-1R treatments. The combination of anti-IGF-1R-HAbs with an antiandrogen therapy is strongly advocated for patients expressing T2E.

\section{INTRODUCTION}

Chromosomal translocations are genetic lesions that are produced by illegitimate recombination events between two non-homologous chromosomes or within the same chromosome and that result in chimeric genes [1]. Although fusion genes have been considered exclusive mutations of lymphomas, leukemias and sarcomas, several tumor-specific rearrangements have been recently identified in carcinomas. In particular, in 2005, a chromosomal rearrangement leading to the fusion of the androgen-regulated gene TMPRSS2 and one of the ETS genes, predominantly $E R G$, was described as being expressed in $40-70 \%$ of prostate cancers (PCas) from a radical prostatectomy series [2]. PCa is one of the most commonly diagnosed cancers in adult men, accounting for $10 \%$ of cancer deaths in Europe [3]. PCa progression is accompanied by genetic mutations, including TMPRSS2$E R G$ (T2E) rearrangement, which is considered an early event because it is found in localized disease more frequently than in high-grade prostatic intraepithelial neoplasia (PIN) [4]. 
Because TMPRSS2 contributes only untranslated sequences, the fusion gene results in the overproduction of a truncated ERG protein (tERG) $[2,5]$. ERG shares with other ETS transcription factors the same DNA-binding domain that recognizes the 5'-GGAA/T-3' motif. ETS proteins are considered proto-oncogenes because they control the expression of target genes involved in cell proliferation, apoptosis and invasion [6]. Studies exploring the functional significance of truncated ERG protein are controversial but suggest that ETS activation promotes epithelial-mesenchymal transition (EMT) and invasiveness [5, 7, 8]. Nevertheless, $\mathrm{T} 2 \mathrm{E}$ has been reported as insufficient to induce a transformed phenotype but instead to cooperate with other mutations [9]. We analyzed the impact of T2E on the insulin-like growth factor (IGF) system. The IGF system is composed of three receptors [insulin receptor (IR), IGF-1 receptor (IGF-1R) and mannose 6-phosphate receptor (M6P/IGF-2R)], three ligands (insulin, IGF-1, IGF-2), and six known types of circulating IGF-binding proteins (IGFBP1-6) that modulate the bioavailability and bioactivity of the IGFs $[10,11]$. The role of the IGF system and particularly IGF-1R in human cancer has been widely documented [11]. In the prostate, IGF-1R plays a critical role in normal gland growth and development, as well as in cancer initiation and progression [12]. Epidemiologic studies have associated circulating IGF-1 levels with risk of developing disease [13-15]. However, numerous experimental and clinical studies have produced controversial evidence, suggesting a need for further studies. Indeed, although the intensity of IGF-1R immunostaining has generally been reported to increase from benign prostatic hyperplasia (BPH) to PIN to carcinoma [16], several studies have not confirmed this linear relationship and have reported that reduced IGF-1R is associated with hyperplasia and proliferation or metastatic lesions [17, 18]. Despite this variation may be due to technical factors, clinical studies evaluating the prognostic role of IGF-1R expression have also provided controversial results, reporting either positive or negative associations between receptor expression levels and patient outcome $[19,20]$. In addition, phase II studies using IGF-1R inhibitors have failed to demonstrate efficacy in castration-resistant $\mathrm{PCa}$ (CRPC) patients [21, 22], putatively due to incomplete pathway blockade, onset of resistance mechanisms or lack of a suitable patients selection. A better understanding of the molecular determinants of aberrant IGF-1R expression in prostate tumors is thus required to define subgroups of patients who may benefit from antiIGF-1R therapies. In this study, we demonstrated that T2E directly binds the $I G F-1 R$ gene promoter, thus affecting its expression and treatment sensitivity in $\mathrm{PCa}$.

\section{RESULTS}

\section{tERG directly binds to the $I G F-1 R$ promoter in prostate cells and modulates IGF-1R expression}

A panel of five prostate cancer cell lines, $\mathrm{VCaP}$, DU-145, PC-3, LNCaP and 22RV1, characterized by different expression levels of the androgen receptor (AR) and T2E gene fusion, and non-malignant RWPE-1 prostate cells (Supplementary Figure S1) was analyzed for the expression of different components of the IGF system. No IGF-1 or IGF-2 expression was found in the cell lines (data not shown), confirming the paracrine activation of the pathway in this tumor. IR expression is generally higher in PCa cell lines with respect to normal cells (Figure 1). This difference is particularly evident at the protein level and does not appear to reflect a regulation at the transcriptional level. In contrast, IGF-1R expression is generally low in malignant cells, with the only notable exception of $\mathrm{VCaP}$ cells, which express the T2E fusion gene. These data were confirmed at the mRNA and protein levels, thus supporting regulation at the transcriptional level for IGF-1R expression (Figure 1).

To better understand the role of tERG in IGF-1R modulation, IGF-1R protein levels were analyzed after ERG siRNA transfection in VCaP cells. A decrease in IGF-1R was evident $96 \mathrm{~h}$ and $120 \mathrm{~h}$ after silencing. Conversely, IGF-1R protein expression was increased both in the non malignant RWPE-1 and malignant PC-3 cells stably transfected for tERG overexpression (RWPE-1_tERG and PC-3 tERG, respectively; Figure 2A), confirming the correlation between IGF-1R and the fusion gene. Moreover, an anti-ERG chromatin immunoprecipitation (ChIP) assay was performed in $\mathrm{VCaP}$ and parental PC-3 cells, which express ERG at high or low levels, respectively, as well as in RWPE-1_tERG cells. ChIP analysis indicated that ERG binds the $I G F-1 R$ gene promoter, and the amount of binding was higher in cells with tERG expression (Figure $2 \mathrm{~B}$ ). No consensus sequences were present in the promoter of IR (data not shown). Because the $\mathrm{T} 2 \mathrm{E}$ fusion gene is regulated by androgens, the naturally expressing T2E VCaP cells were treated with abiraterone acetate, and IGF-1R protein levels were investigated upon stimulation. Abiraterone acetate is a second-generation anti-androgen drug that blocks the synthesis of androgens through the inhibition of $17 \alpha$-hydroxylase/C17, 20 lyase (CYP17A1). VCaP cells were treated for 72,96 and $120 \mathrm{~h}$ with two concentrations of abiraterone acetate, and western blotting analysis showed that together with a strong ERG down-regulation, IGF-1R levels decreased upon $10 \mu \mathrm{M}$ treatment in VCaP cells (Figure 2C).

\section{tERG overexpression increases sensitivity to anti-IGF-1 $R$ agents}

PCa cell lines were exposed to increasing concentrations of CP-751,871 or AVE1642, two anti-IGF1R-HAbs, as well as NVP-AEW541, a selective IGF1R tyrosine kinase inhibitor (TKI) [23-26]. As shown in Figure 3A, only VCaP cells showed remarkably high sensitivity to all anti-IGF-1R agents compared with the other PCa cell lines. Accordingly, PC-3_tERG cells showed increased sensitivity to $\mathrm{CP}-751,8 \overline{7} 1$ treatment compared to empty vector transfected cells. To address the role of the T2E/IGF-1R axis in influencing sensitivity to 

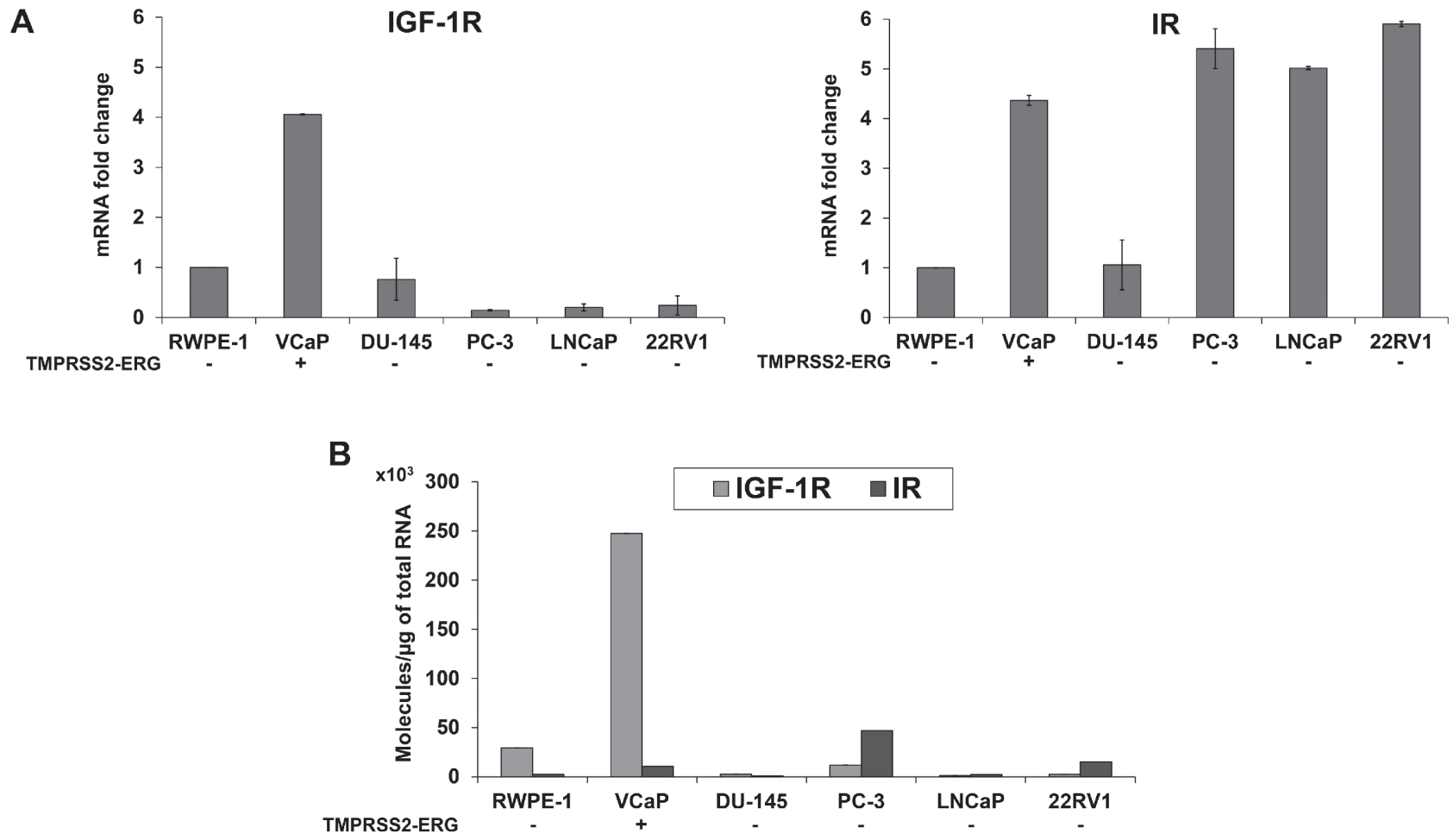

C

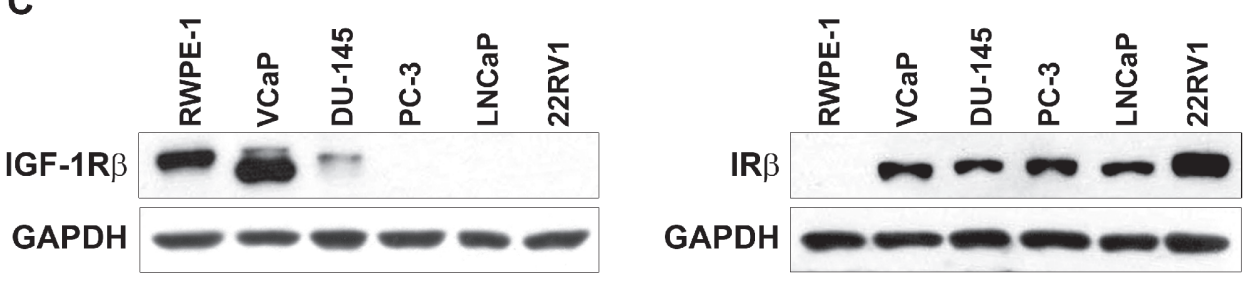

Figure 1: Evaluation of IGF-1R and IR basal expression in prostate cell lines. (A) Relative mRNA expression levels of $I G F-1 R$ and $I R$ in prostate cancer cell lines. The RWPE-1 cell line was used as a calibrator $\left(2^{-\Delta \Delta \mathrm{Ct}}=1\right)$. The columns represent the mean values of two independent experiments, and the bars represent the SE. (B) Absolute $I G F-I R$ and $I R$ mRNA quantification was assessed in the panel of cells. (C) Protein expression levels of receptors in prostate cells. The blots are representative of two independent experiments.

IGF-1R inhibitors, VCaP cells as well as PC-3 tERG cell line were deprived of ERG. The level of ERG expression significantly influenced the efficacy of anti-IGF-1R agents because its silencing cells reverted cell sensitivity toward CP-751,871 or NVP-AEW541 (Figure 3B). Notably, in prostate cancer, several clinical trials have investigated the effects of IGF-1R inhibitors in combination with other drugs, such as mitoxantrone (NCT00683475) or docetaxel [27]. Thus, because TMPRSS2-ERG expression is driven by androgens, we first investigated the response to abiraterone acetate in $\mathrm{VCaP}$ cells upon ERG silencing and observed that these genetically modified cells showed a significant decrease in sensitivity to abiraterone stimulation (Figure 4A). Interestingly, the simultaneous administration of anti-IGF-1R CP-751,871 HAbs and abiraterone but not cabazitaxel, a microtubule inhibitor recently introduced in $\mathrm{PCa}$ treatment, induced synergistic antiproliferative effects in VCaP cells (Figure 4B). Conversely, combined treatment of CP-751,871 and abiraterone gave subadditive effects in T2E-null DU-145 and LNCaP cell lines $(\mathrm{CI}=$ $2.88 \pm 1.17$ and $\mathrm{CI}>100$, respectively).

\section{IGF-1R levels are associated with T2E expression in clinical samples}

To confirm the clinical relevance of our experimental observations, we examined the gene expression levels of $I G F-1 R$ by qRT-PCR in a retrospective cohort of 270 primary prostate tumors (Figure 5A). Fisher's test revealed an association between $I G F-1 R$ and $\mathrm{T} 2 \mathrm{E}$ expression in clinical samples $(p=0.008)$. In particular, patients harboring the fusion gene showed higher $I G F-1 R$ mRNA levels, in keeping with the increased binding of ERG to the $I G F-1 R$ promoter. This association was confirmed at the protein level. We analyzed the protein expression of ERG and IGF$1 \mathrm{R}$ in the same series of patients (Table 1). IGF-1R and ERG expression at the mRNA and protein levels (evaluation scores are reported in the Materials and Methods) were 


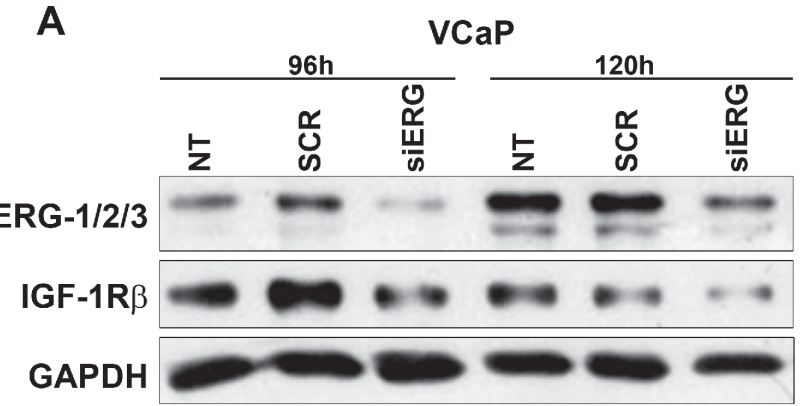

RWPE-1

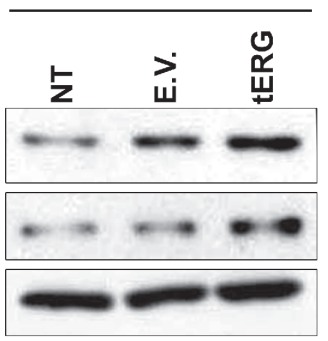

PC-3

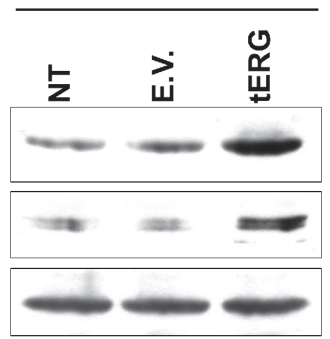

B IGF-1R promoter analysis
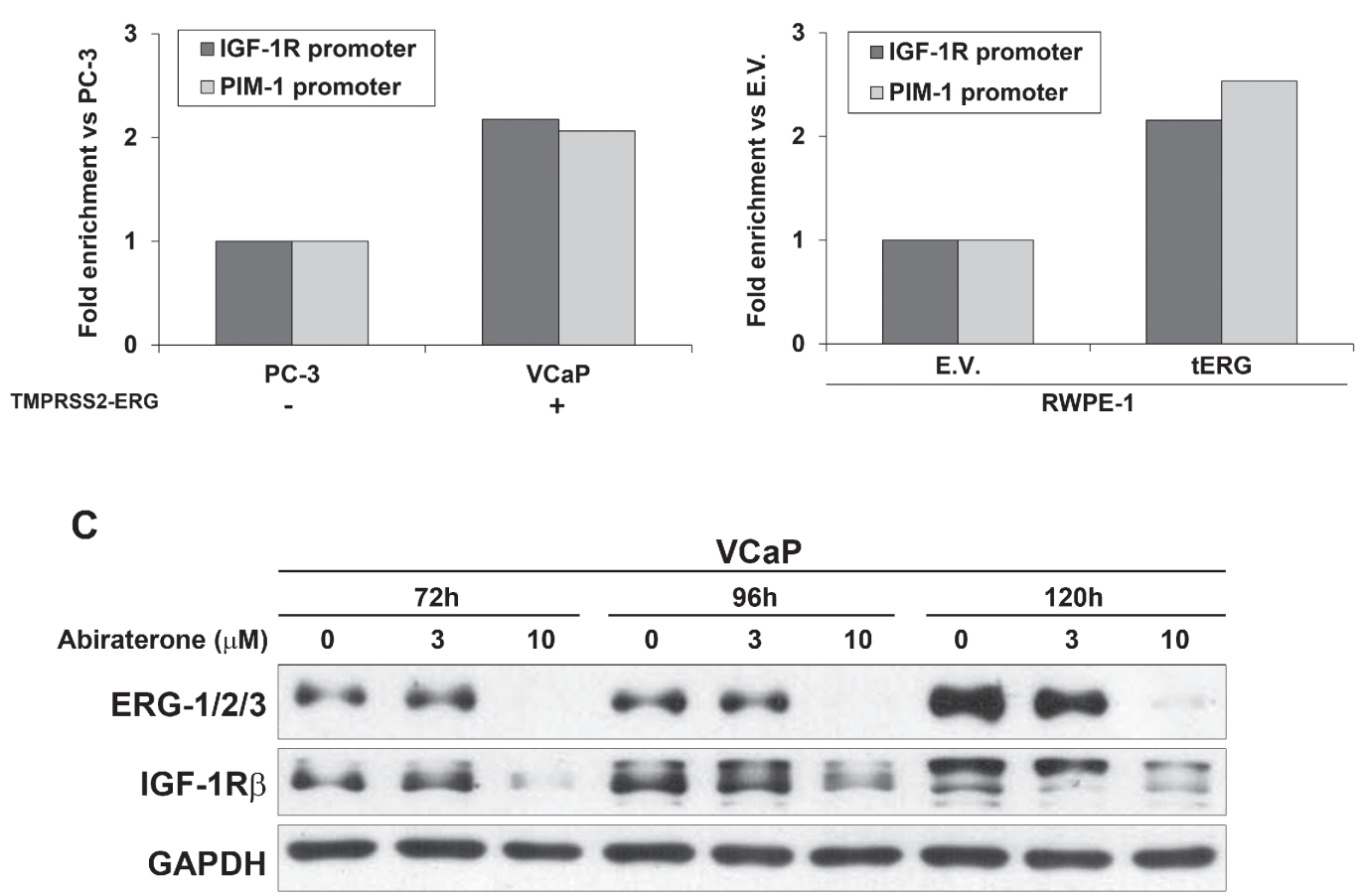

Figure 2: tERG-dependent IGF-1R induction in prostate cancer cells. (A) siRNA knockdown of ERG (siERG) in VCaP induces a decrease in IGF-1R levels compared with non-treated control (NT) or non-targeting siRNA (SCR) controls, whereas IGF-1R is overexpressed in RWPE-1 and PC-3 cells transfected with tERG compared with empty vector-transfected cells. The blots are representative of two independent experiments. GAPDH is shown as a loading control. (B) A ChIP assay was performed on VCaP and PC-3 prostate cancer cells, as well as on tERG- or empty vector-transfected RWPE-1 cells. ERG was precipitated with an anti-ERG-1/2/3 antibody. The results were obtained by quantitative RT-PCR. The data represent the recovery of each DNA fragment relative to the total input DNA. (C) Abiraterone acetate treatment induces down-regulation of ERG in VCaP cells and, consequently, down-regulation of IGF-1R. Cells were treated with abiraterone ( 3 and $10 \mu \mathrm{M}$ ) for the indicated time points. Representative blots are shown. GAPDH was used for normalization.

significantly correlated $(p=0.047$ and $p<0.0001$; Fisher's test, respectively). As observed at the mRNA level, IGF$1 \mathrm{R}$ protein expression was also found to be significantly associated with ERG expression ( $p<0.0001$; Fisher's test), further verifying the association between IGF-1R and T2E (Figure 5B).

\section{DISCUSSION}

The T2E fusion gene constitutes a critical event in development of $\mathrm{PCa}[2,28]$, but other genetic alterations, such as loss of PTEN and PI3K pathway activation, are also required to induce malignant transformation [8]. Here, we provide evidence that IGF-1R is a target of tERG from $\mathrm{T} 2 \mathrm{E}$ translocation and that this interaction has important implications in the field of personalized treatment through biomarker-driven patient selection. ChIP analysis showed ERG binding to the $I G F-1 R$ gene promoter, suggesting a direct transcriptional regulation of $I G F-1 R$ by ERG. Furthermore, we found greater ERG recruitment to the $I G F-1 R$ promoter in $\mathrm{VCaP}$ cells compared with $\mathrm{PC}-3$ cells expressing low ERG levels, as well as in RWPE-1 
A

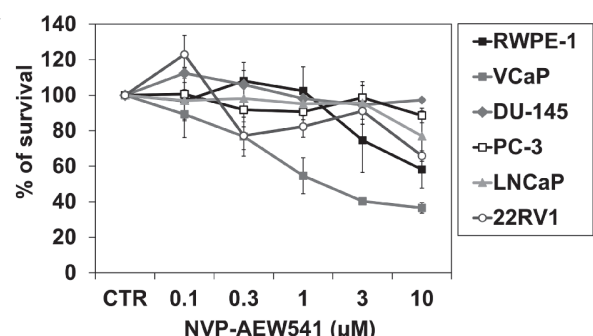

B
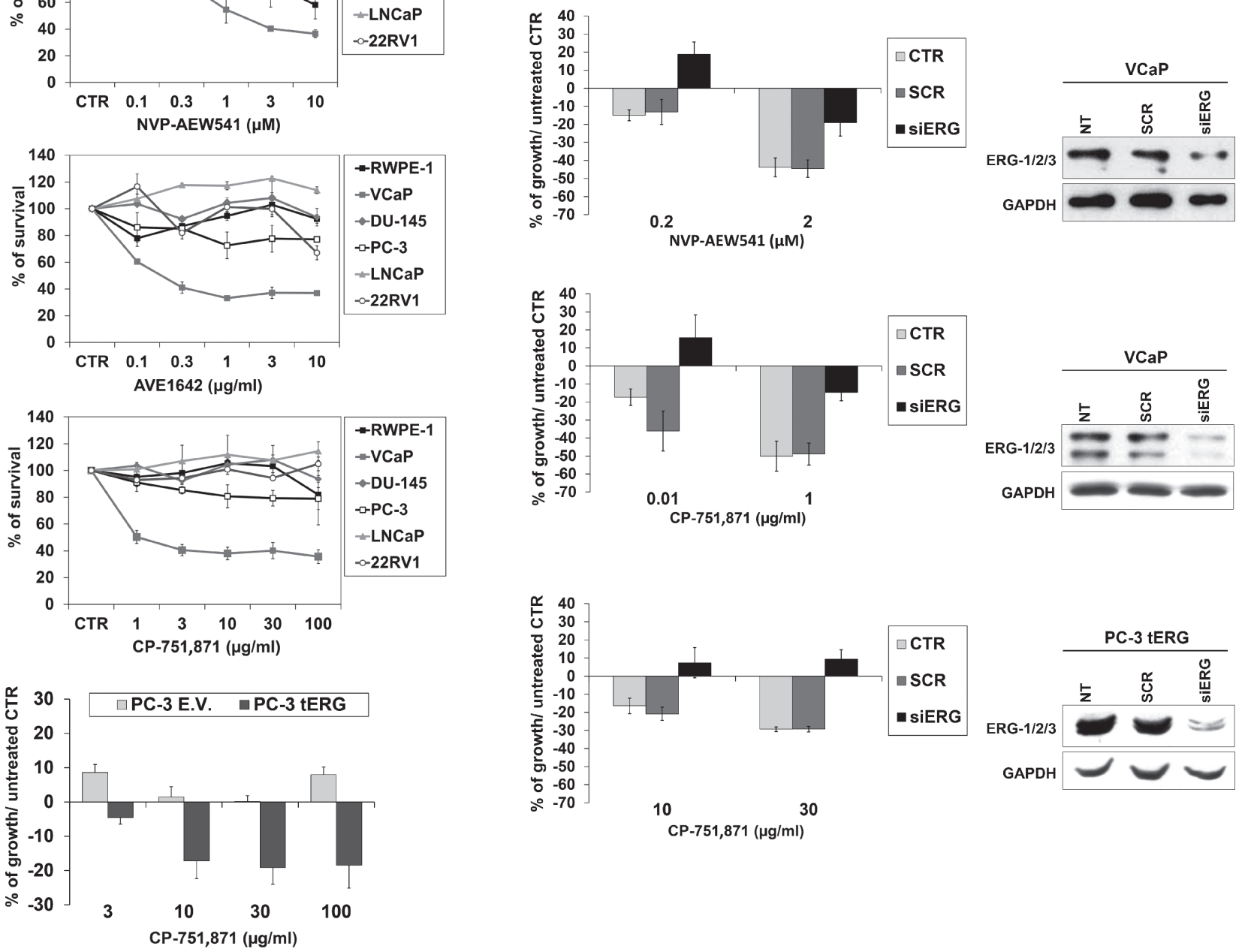

Figure 3: Efficacy of anti-IGF-1R agents in prostate cancer cells. (A) Cell growth was assessed using an MTT assay after a 72-h exposure to CP-751,871 or AVE1642, two anti-IGF-1R-HAbs, and NVP-AEW541, an anti-IGF-1R tyrosine kinase inhibitor (TKI) in prostate cell lines. PC-3 cells transfected with tERG or PC-3 empty vector-transfected cells were treated with indicated doses of CP-751,871 for $72 \mathrm{~h}$. The results are displayed as the percentage of survival relative to controls. Points, mean of two independent experiments; bars, SE. (B) Reversion of sensitivity to anti-IGF-1R therapies by ERG knockdown. ERG silencing was achieved in VCaP or PC-3_tERG cells after a $48 \mathrm{~h}$ transfection of siERG $(100 \mathrm{nM})$ or scrambled control siRNA (100 nM); GAPDH was used as a loading control. The transfected cells were treated as described in the Materials and Methods. Cell survival is shown as the percentage of growth respect to untreated control. The data represent the mean values of two independent experiments, and the bars represent the SE.

cells that over-expressed tERG compared with the empty vector. As a proof of concept, androgen deprivation induced by abiraterone acetate treatment in the androgenresponsive $\mathrm{VCaP}$ cells caused a significant decrease in ERG expression, as previously reported [29], but also a consequent inhibition of IGF-1R, confirming the presence of a T2E/IGF-1R androgen-regulated axis. Considering that RWPE-1 represents a model of non-tumorigenic immortalized cells but that $\mathrm{VCaP}$ cells are representative of advanced disease, the data indicate that the T2E/IGF-1R axis may represent a constant mechanism along different stages of pathology with putatively different consequences depending on pathological stage. The relationship between T2E and IGF-1R was also confirmed in radical prostatectomy specimens; patients expressing the fusion gene exhibited higher IGF-1R expression.

The $I G F-1 R$ gene has been identified as a molecular target for a number of stimulatory transcription factors and inhibitory proteins with important implications in cancer [30]. Aberrant fusion products, such as EWSWT1 or EWS-FLI, the genetic hallmarks of desmoplastic small round cell tumor or Ewing sarcoma, were found to act as transactivators for the IGF-1R system, providing a selective growth advantage to tumor cells [31, 32]. 
A
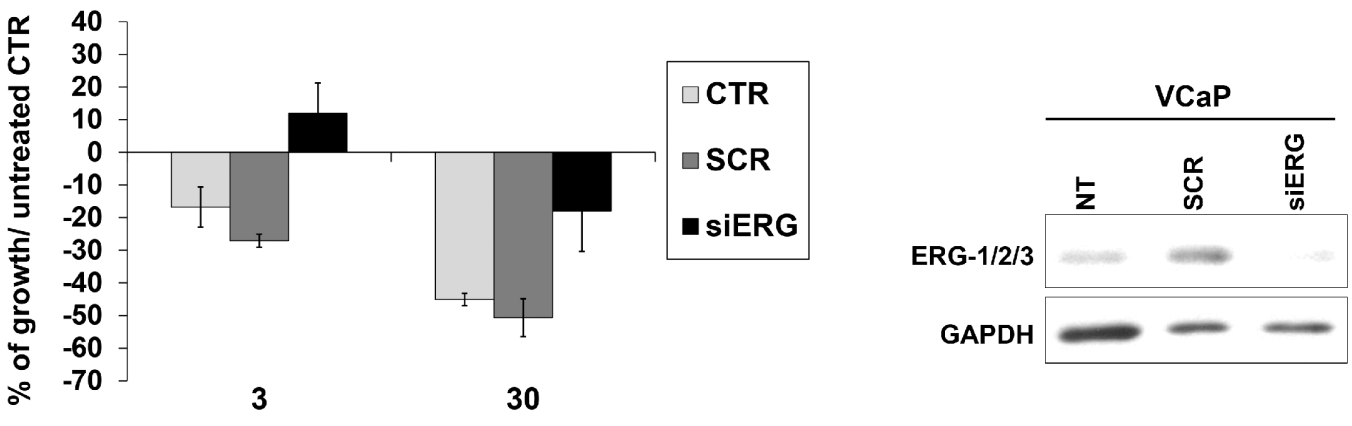

Abiraterone acetate $(\mu \mathrm{M})$

B
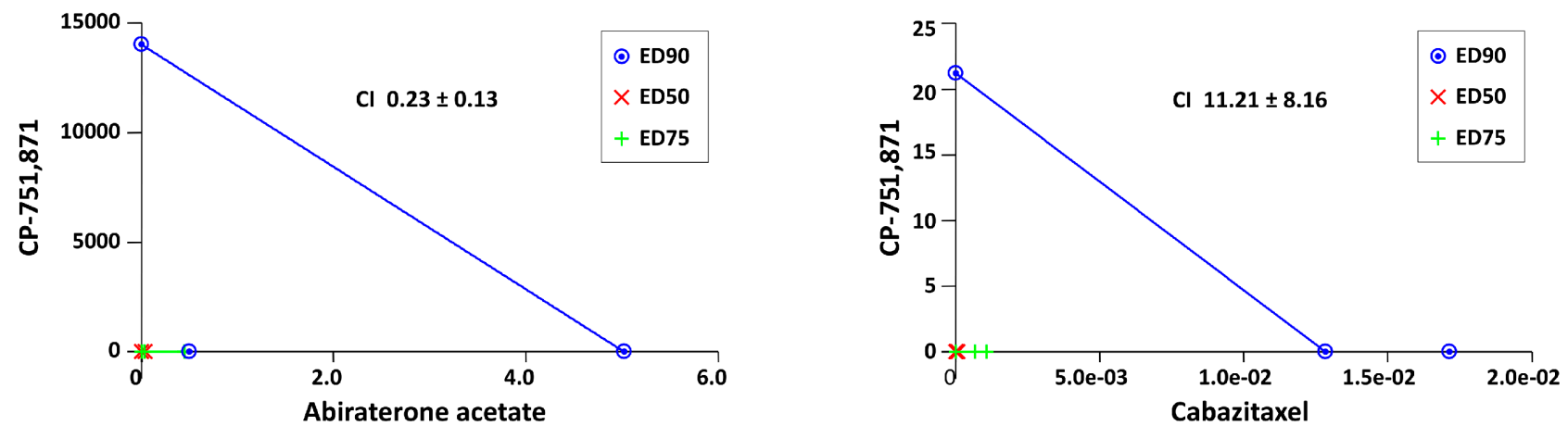

Figure 4: The combination of an IGF-1R inhibitor with an anti-androgen drug results in synergistic effects in TMPRSS2-ERG-positive cells. (A) ERG was silenced in VCaP cells with siERG (100 nM) or scrambled control siRNA (100 nM); GAPDH was used as a loading control. Cells were treated with abiraterone acetate for $72 \mathrm{~h}$ at the indicated doses, and the survival percentage with respect to untreated control is shown. The data represent the mean values of two independent experiments, and the bars represent SE. (B) The effects of simultaneous combined treatments of CP-751,871 in association with abiraterone acetate or cabazitaxel. Individual doses of CP-751,871, abiraterone acetate or cabazitaxel to achieve 90\% growth inhibition (blue line; ED90), $75 \%$ growth inhibition (green line; ED75) and 50\% (red line; ED50) growth inhibition are plotted on the $\mathrm{x}$ - and y-axes. CI values are represented by the points above on (indicating synergy), or below (indicating antagonism) the lines. The CI values representing ED90 are reported.

From a biological standpoint, the T2E/IGF-1R axis may be assumed to participate in establishing a biologically distinguished cellular context and promote a malignant cellular phenotype compared with cells that do not express T2E. From the clinical standpoint, this mechanism provides the rationale for the selective use of anti-IGF$1 \mathrm{R}$ agents for patients expressing the fusion gene. The contribution of IGF-1R to prostate carcinogenesis and progression remains controversial, but epidemiological, preclinical and clinical results indicate that IGF-1R overexpression plays an important role in the pathogenesis of CRPC [33]. This evidence in particular led to the enrollment of CRPC patients in several clinical trials investigating the effects of IGF-1R inhibitors. However, these clinical trials verified only very modest clinical benefits from IGF-1R inhibition $[22,27]$ and resulted in discontinuing the development of most of anti-IGF-1R agents. Here, we demonstrated that only $\mathrm{PCa}$ cells that express the translocation and therefore have higher IGF$1 \mathrm{R}$ expression displayed potentially interesting sensitivity to anti-IGF-1R agents. Accordingly, ERG silencing caused a decrease in treatment sensitivity, thus supporting the idea that only patients with PCa presenting with T2E may benefit from anti-IGF-1R therapy. This idea is in line with previous evidence demonstrating how PARP1 inhibitors blocked ETS-positive but not ETS-negative prostate cancer xenograft growth [34]. In addition, consistent with the observation that T2E-positive CRPC tumors display a better response to anti-androgen treatment compared with T2E-negative tumors [35], we found that sensitivity to abiraterone acetate significantly decreased upon ERG silencing. Abiraterone acetate is a selective small molecule inhibitor of CYP17, an enzyme that catalyzes generation of androgens and estrogens. In the clinic, the onset of androgen receptor-linked resistance mechanisms in CRPC patients treated with abiraterone is an important limitation, and the identification of a druggable target involved in the androgen receptor pathway may be an interesting opportunity to overcome resistance [36]. Combined therapies with abiraterone and targeted agents, such as Src inhibitors [37] or PI3K pathway inhibitors [38], have been proposed. Our results provide evidence for the first time 

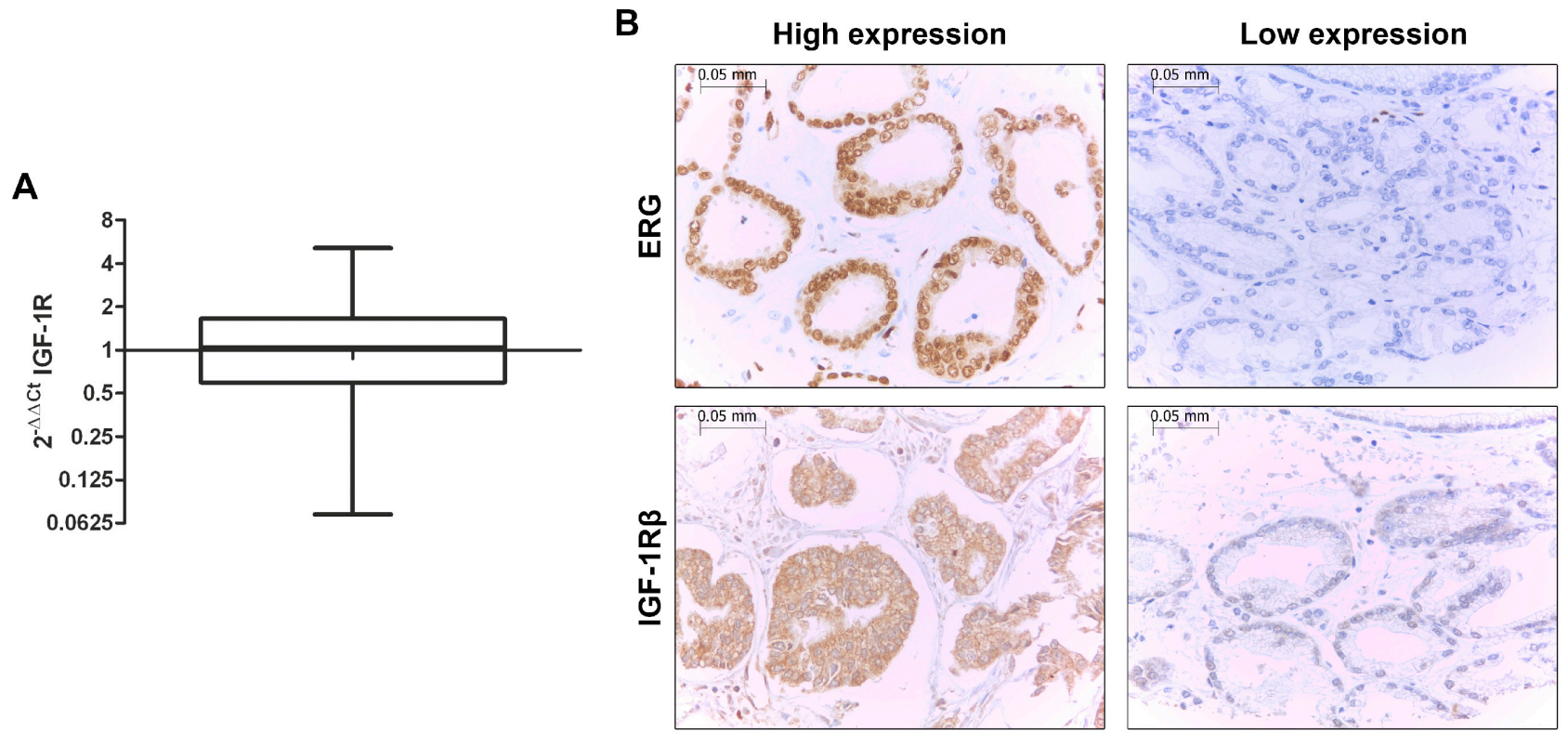

Figure 5: The fusion gene is directly correlated with IGF-1R in prostate cancer patients. (A) $I G F-1 R$ expression profile in 270 FFPE primary prostate cancer samples analyzed by qRT-PCR. Normal tissues were used as calibrator. $I G F-1 R$ was not differentially expressed with respect to normal tissue (median $=1.04$; range $=0.07-5.12$ ). (B) Representative expression of ERG (top) and IGF-1R (bottom) in prostate cancer tissue array samples by immunohistochemistry (magnification, x40). The cases were classified as 'highexpressors' when medium or high positivity was present and 'low-expressors' when no staining or low positivity was observed.

of a beneficial combination of abiraterone acetate and antiIGF-1R agents. In VCaP cells, the association of anti-IGF1R CP-751,871 HAb with abiraterone acetate produced synergistic effects, supporting the idea that the concurrent use of the two targeted agents deprive tERG-expressing cells of fundamental signaling pathways that operate in concert to sustain cell proliferation.

Overall, we suggest the application of $\mathrm{T} 2 \mathrm{E}$ as a biomarker for patient selection in the field of personalized medicine. We demonstrated that IGF-1R is an important target of tERG and that this interaction leads to a higher IGF-1R expression in cell lines and patients. Thus, we observed a good response to IGF-1R inhibition in T2E-positive cells compared with T2E-negative cells. Considering that such a mechanism is driven by androgens, we provide the rationale for combining anti-IGF-1R agents to anti-androgen therapy in the subpopulation of patients expressing T2E.

\section{MATERIALS AND METHODS}

\section{Cell lines}

Prostate cancer cell lines PC-3, LNCaP, DU-145, $\mathrm{VCaP}$ were obtained from the American Type Culture Collection (ATCC). 22RV1 prostate cancer cell line was purchased from Sigma Aldrich. Immortalized nonmalignant prostate cell line RWPE-1 and stable trasfectants RWPE-1_tERG or RWPE-1_empty vector were kindly provided by Dr. Gambacorti-Passerini, University of
Milano-Bicocca [39]. PC-3, LNCaP and DU-145 cells were cultured in Iscove's Modified Dulbecco's Medium (IMDM) (Lonza). RWPE-1 and transfectant cells were maintained in keratinocyte-serum free medium supplemented with epidermal growth factor and bovine pituitary extract (Life Technologies Inc.). 22RV1 cells were maintained in RPMI 1640 (Gibco) while VCaP cells were maintained in Dulbecco's Modified Eagle's Medium (DMEM) (Sigma) implemented with L-glucose and bicarbonate. IMDM, RPMI and DMEM media were supplemented with $10 \%$ inactivated Fetal Bovine Serum (FBS) (Lonza) and 100 units $/ \mathrm{ml}$ penicillin and $100 \mu \mathrm{g} / \mathrm{ml}$ streptomycin. Cells were maintained at $37^{\circ} \mathrm{C}$ in a humidified $5 \% \mathrm{CO}_{2}$ atmosphere. All cell lines were tested for mycoplasma contamination every 3 months by MycoAlert mycoplasma detection kit (Lonza) and were recently authenticated by STR PCR analysis using genRESVR MPX-2 and genRESVR MPX-3 kits (Serac). The following locus were verified: D3S1358, D19S433，D2S1338，D22S1045，D16S539，D18S51, D1S1656, D10S1248, D2S441, TH01, VWA, D21S11, D8S1179, FGA, SE33.

\section{Clinical prostate specimens}

Formalin fixed and paraffin-embedded (FFPE) blocks corresponding to $\mathrm{PCa}$ patients were retrieved from the archives of the Biobank of the Fundación Instituto Valenciano de Oncología according to the following criteria: specimens obtained from radical retropubic prostatectomies from 1996 to 2002 and no history of 
Table 1: Clinicopathologic features of the analyzed series

\begin{tabular}{|c|c|c|c|c|}
\hline \multirow[b]{2}{*}{ Parameter } & \multicolumn{2}{|c|}{ qRT-PCR $(n=270)$} & \multicolumn{2}{|c|}{ IHC $(n=243)$} \\
\hline & No. Pts & $\%$ & No. Pts & $\%$ \\
\hline \multicolumn{5}{|l|}{ Age } \\
\hline$\leq 55$ & 15 & 5,6 & 12 & 5 \\
\hline $56-65$ & 81 & 30 & 74 & 31 \\
\hline $66-75$ & 138 & 51,1 & 124 & 52,1 \\
\hline$>75$ & 36 & 13,3 & 28 & 11,7 \\
\hline \multicolumn{5}{|l|}{ Gleason-sp: } \\
\hline $2-6$ & 109 & 40,4 & 87 & 36,4 \\
\hline 7 & 129 & 47,8 & 123 & 51,4 \\
\hline Greater than 7 & 32 & 11,9 & 29 & 12,1 \\
\hline \multicolumn{5}{|l|}{ PSA (ng/ml): } \\
\hline 10 or less & 154 & 57 & 132 & 55,6 \\
\hline $10-20$ & 74 & 27,6 & 69 & 29,1 \\
\hline Greater than 20 & 40 & 14,9 & 36 & 15,1 \\
\hline \multicolumn{5}{|l|}{ cT: } \\
\hline $\mathrm{cT} 2 \mathrm{~b}$ or less & 248 & 92,2 & 219 & 92 \\
\hline cT3a or greater & 21 & 7,8 & 19 & 7,9 \\
\hline \multicolumn{5}{|l|}{ pT: } \\
\hline pT2 or less & 135 & 50 & 115 & 48,1 \\
\hline pT3 or greater & 135 & 50 & 124 & 51,8 \\
\hline \multicolumn{5}{|l|}{$\mathrm{pN}^{*}:$} \\
\hline $\mathrm{pNO}$ & 236 & 95,2 & 209 & 95,4 \\
\hline $\mathrm{pN} 1$ or greater & 12 & 4,8 & 10 & 4,5 \\
\hline \multicolumn{5}{|l|}{ Margins: } \\
\hline Negative & 137 & 50,7 & 116 & 48,5 \\
\hline Positive & 133 & 49,3 & 123 & 51,4 \\
\hline \multicolumn{5}{|l|}{ TMPRSS2-ERG** } \\
\hline Negative & 92 & 34,1 & 102 & 46,5 \\
\hline Positive & 178 & 65,9 & 117 & 53,4 \\
\hline \multicolumn{5}{|l|}{$\mathrm{IGF}-1 \mathrm{R} * * *$} \\
\hline Low expressors & 82 & 30,4 & 55 & 24,7 \\
\hline High expressors & 188 & 69,6 & 167 & 75,2 \\
\hline
\end{tabular}

SP, specimen; cT, clinical stage; PSA, prostatic specific antigen; pN, lymphnode pathological stage

*Lymphadenectomy was limited to the obturator fossa in most of the cases at the inclusion period

$* *$ IHC ERG expression was not detectable in $24 / 243$ and negative in $85 / 219$ cases (39\%)

$* * *$ IHC IGF-1R expression was not detectable in $21 / 243$ cases and negative in $12 / 222$ of the samples (5\%). 
previous treatment for $\mathrm{PCa}$ (including androgen deprivation therapy or chemotherapy prior to surgery). We identified 270 cases that met these criteria. All patients gave written informed consent for tissue donation for research purposes before tissue collection, and the study was approved by FIVO's Institutional Ethical Committee (ref. number. 201019). Clinical data were reviewed from clinical records and stored in a PCa-specific database. Patient characteristics, including the T2E fusion gene status, and demographics are shown in Table 1. Combined Gleason score was uniformly regarded by the same uro-pathologist (AC). For comparative and calibration purposes, we also analyzed 10 samples of normal prostate tissue obtained from patients operated of radical cystectomies without pathological evidence of prostatic disease. T2E gene fusion status was determined by RT-PCR and fluorescent in situ hybridization (FISH) as already described [40] and quantitative RT-PCR.

\section{Gene expression analysis}

Cell lines total RNA (2 mg) was extracted with TRIzol (Invitrogen) and purified by precipitation with isopropanol. Oligo dT primers (Applied Biosystems) were used to reverse transcribe RNA. Isolation of RNA from paraffinembedded tissue was performed using RecoverAll ${ }^{\text {TM }}$ Total Nucleic Acid Isolation Kit (Ambion) following providers' specifications and reverse transcription was performed with High Capacity cDNA Reverse Transcription Kit (Applied Biosystems) according to manufacturer's indications. For cell line analysis, Quantitative Real-Time PCR was performed on ABI Prism 7900 (Applied Biosystems) using TaqMan $(I G F-1 R)$ or SYBR Green assays (IR) (Applied Biosystems) as previously reported [26]. Primer Express software (Applied Biosystems) was used to design appropriate primer pairs for reference gene (glyceraldehyde3-phosphate dehydrogenase) [26]. Clinical samples were analyzed using ABI 7500-Fast Thermocycler Sequence Detection System (Applied Biosystems), according to manufacturer's instructions. Predesigned TaqMan probes for target genes $I G F-1 R$ (Hs00181385_m1), T2E (Hs03063375_ft) as well as for endogenous control $\beta$-2microglobulin (Hs99999907_m1) were used (Applied Biosystem). Two replicates per gene were considered. Relative quantification analysis was performed on $\Delta \Delta \mathrm{Ct}$ method [41]. cDNA from normal human prostate samples was used as calibrator for comparative analysis of $\mathrm{PCa}$ cases. Absolute quantification assay was performed for the measurement of total $I R$ and $I G F-1 R$ [42].

\section{Western blotting}

Cell lysates were prepared and processed as previously described [43]. Membranes were incubated overnight with the following primary antibodies: antiIGF-1R $\beta$, anti-IR $\beta$, anti-GAPDH, anti-LAMIN B, anti-ERG-1/2/3 (Santa Cruz Biotechnology); anti-AR (Cell Signaling Technology); anti-rabbit or anti-mouse antibodies conjugated to horseradish peroxidase (GE Healthcare) were used as secondary antibodies.

\section{Drugs}

Anti-IGF-1R drugs were kindly provided by: ImmunoGen Inc. (AVE1642, a humanized version of anti-IGF-1R EM164 antibody), Pfizer (CP-751,871/ Figitumumab), and Novartis (NVP-AEW541). Abiraterone acetate (S1123) and Cabazitaxel (S3022) were purchased by Selleckchem.

\section{In vitro assays}

To assess drug sensitivity, MTT assay (Roche) was used according to manufacturer's instructions. Cells were plated into 96 well-plates (10, 000 cells/well). After 24 hours, various concentrations of AVE1642 $(0.01-50 \mu \mathrm{g} / \mathrm{ml})$, NVP-AEW541(0.03-5 $\mu \mathrm{M})$, Figitumumab $(0.5-500 \mu \mathrm{g} / \mathrm{ml})$ were added and cells exposed to these drugs for up to 72 hours. phCMV2_HA_tERG plasmid containing the cDNA of the translated sequence of TMPRSS2-ERG (isoform 9) and phCMV2 empty vector were kindly provided by Dr. Gambacorti-Passerini, University of Milano-Bicocca [39]. PC-3 cell line was stably transfected with Calcium Phosphate Transfection Kit (Invitrogen) accordingly to manufacturer's instruction and selected for geneticin (Sigma) resistance at $0.75 \mathrm{mg} / \mathrm{ml}$. PC-3_tERG and PC-3 empty vector transfected cells were treated with CP-751,871 $(3,10,30,100 \mu \mathrm{g} / \mathrm{ml})$ for up to 72 hours and sensitivity was assessed with Trypan Blue cell count. Short interfering RNA knockdown of ERG was performed with siRNA from Thermo Scientific Dharmacon: siGENOME siRNA (D-003886-01) as reported in Tomlins et al. [5] and Magistroni et al. [39]. siGENOME_non targeting siRNA was used as control (D-001210-01-05). siRNA was transfected in VCaP or PC-3_tERG cells using siport NeoFX transfection agent (Life Technologies Inc.) according to manufacturer's instructions. Silencing was assessed after 48, 72, 96 and 120 hours from transfection. VCaP cells were pre-treated with ERG siRNA (100 nM) for 48 hours and then exposed to CP-751,871 (0.01-1 $\mu \mathrm{g} / \mathrm{ml})$, NVP-AEW541 $(0.2-2 \mu \mathrm{M})$ or Abiraterone $(3-30 \mu \mathrm{M})$ for 72 hours. PC-3 tERG cells were pre-treated with ERG siRNA $(100 \mathrm{nM})$ for 48 hours and then exposed to CP-751,871 $(10-30 \mu \mathrm{g} / \mathrm{ml})$. ERG and IGF-1R protein expression was investigated upon 72, 96 and 120 hours of Abiraterone treatment $(3-10 \mu \mathrm{M})$. For combined treatments, LNCaP, DU-145 and VCaP cells were treated for 72 hours with varying concentrations of CP-751,871 (1-100 $\mu \mathrm{M})$ and Abiraterone $(1-100 \mu \mathrm{M})$ or Cabazitaxel $(0.003-0.3 \mu \mathrm{M})$.

\section{Chromatin immunoprecipitation (ChIP)}

ChIP assay was performed as previously described [43, 44] using anti-ERG-1/2/3 antibody (C-17, Santa Cruz Biotechnology). $I G F-1 R$ promoter was evaluated by 
Real-Time PCR using the following custom TaqMan assay: forward 5'-AGGAGGAGGAGGAGG AGGAG-3', reverse 5'-GCAGTTCGCAAGATCGCC-3'

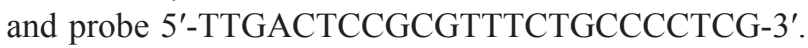
For the TaqMan assay design TFSEARCH - Searching Transcription Factor Binding Sites, version 1.3 free website was used for the prediction of ETS binding sites in the promoter of $I G F-1 R$ gene and the sequence spanning from $1041 \mathrm{bp}$ to $1051 \mathrm{bp}$ was identified as the best. Beacon Designer 4 software was used for the design of the assay spanning from $1005 \mathrm{bp}$ to $1114 \mathrm{bp}$. PIM-1 promoter fragment containing ETS consensus sequence was used as immunoprecipitation positive control [39] by Real-Time PCR using the following SYBR Green assay: forward 5'-GTGCTAGGCGAGTGGGAACAACTG-3' and reverse 5'-AATGACCCAAATTCACCTCCTGAG-3'. Quantification analysis was calculated with the following formula: $\%$ of recruitment $=2^{\Delta \mathrm{Ct}} \mathrm{x}$ input chromatin percentage where $\Delta \mathrm{Ct}=\mathrm{Ct}$ (INPUT) - $\mathrm{Ct}$ (IP:ERG) [45].

\section{Immunohistochemistry}

$\mathrm{PCa}$ specimens were incorporated in 11 tissue microarrays (TMA). Two or three representative areas (1 $\mathrm{mm}$ in diameter) of each tumor were selected for TMA production by first examining hematoxylin and eosinstained prostatectomy tumor slides and then sampling tissue from the corresponding paraffin blocks. A tissue microarray instrument (Beecher Instruments) was used for TMA assembly. From TMA blocks, $3-\mu \mathrm{m}$-thick sections were immunostained using rabbit anti-human IGF-1R $\beta$ (Santa Cruz Biotechnology) or anti-human ERG clone EP111 polyclonal-Ab (Dako). Percentage of IGF-1Rpositive cells and cytoplasmic staining intensity were scored semiquantitatively, forming four groups (from 0 to 3 ). Cases were scored as low expression when staining intensity was between 0 and 1 , and high expression when intensity was 2 and 3.

\section{Statistical analysis}

Differences among means where analyzed using two-sided Student's $t$ test. To define drug-drug interactions combination index (CI) was calculated with the isobologram equation [46] using CalcuSyn software (Biosoft). Correlations analysis was performed using Fisher's exact test.

\section{ACKNOWLEDGMENTS}

The authors thank María García Flores, Tania Mazcuñán Vitiello and Patricia Carretero Hinojosa for technical assistance and the Biobank of the Fundación Instituto Valenciano de Oncología for providing the biological samples for the analysis. We thank Roberta Malaguarnera, University Magna Graecia, for her support in receptors quantification and Cristina Ghinelli and Alba Balladelli for manuscript editing. We also thank the University of Valencia for primer design.

\section{GRANT SUPPORT}

This work was financially supported by the Italian Ministry of Research and Instruction (F.I.R.B. project number: RBAP11884 M 005), the Italian Association for Cancer Research (Katia Scotlandi - AIRC Project N.14049) and the Instituto de Salud Carlos III (PI10/01206 and FPI11/00505), Madrid, Spain. Selena Ventura is in receipt of the fellowship "Guglielmina Lucatello e Gino Mazzega” granted by Fondazione Italiana per la Ricerca sul Cancro - FIRC.

\section{CONFLICTS OF INTEREST}

No potential conflicts of interest were disclosed by the authors.

\section{REFERENCES}

1. Kowarz E, Dingermann T, Marschalek R. Do non-genomically encoded fusion transcripts cause recurrent chromosomal translocations? Cancers (Basel). 2012; 4:1036-1049.

2. Tomlins SA, Rhodes DR, Perner S, Dhanasekaran SM, Mehra R, Sun XW, Varambally S, Cao X, Tchinda J, Kuefer R, Lee C, Montie JE, Shah RB, Pienta KJ, Rubin MA, Chinnaiyan AM. Recurrent fusion of TMPRSS2 and ETS transcription factor genes in prostate cancer. Science. 2005; 310:644-648.

3. Jemal A, Bray F, Center MM, Ferlay J, Ward E, Forman D. Global cancer statistics. CA Cancer J Clin. 2011; 61:69-90.

4. Salami SS, Schmidt F, Laxman B, Regan MM, Rickman DS, Scherr D, Bueti G, Siddiqui J, Tomlins SA, Wei JT, Chinnaiyan AM, Rubin MA, Sanda MG. Combining urinary detection of TMPRSS2:ERG and PCA3 with serum PSA to predict diagnosis of prostate cancer. Urol Oncol. 2013; 31:566-571.

5. Tomlins SA, Laxman B, Varambally S, Cao X, Yu J, Helgeson BE, Cao Q, Prensner JR, Rubin MA, Shah RB, Mehra R, Chinnaiyan AM. Role of the TMPRSS2ERG gene fusion in prostate cancer. Neoplasia. 2008; 10:177-188.

6. Rahim S, Beauchamp EM, Kong Y, Brown ML, Toretsky JA, Uren A. YK-4-279 inhibits ERG and ETV1 mediated prostate cancer cell invasion. PLoS One. 2011; 6:e19343.

7. Carver BS, Tran J, Gopalan A, Chen Z, Shaikh S, Carracedo A, Alimonti A, Nardella C, Varmeh S, Scardino PT, Cordon-Cardo C, Gerald W, Pandolfi PP. Aberrant ERG expression cooperates with loss of PTEN 
to promote cancer progression in the prostate. Nat Genet. 2009; 41:619-624.

8. Klezovitch O, Risk M, Coleman I, Lucas JM, Null M, True LD, Nelson PS, Vasioukhin V. A causal role for ERG in neoplastic transformation of prostate epithelium. Proc Natl Acad Sci U S A. 2008; 105:2105-2110.

9. Shen MM, Abate-Shen C. Molecular genetics of prostate cancer: new prospects for old challenges. Genes Dev. 2010; 24:1967-2000.

10. Pollak M. Insulin and insulin-like growth factor signalling in neoplasia. Nat Rev Cancer. 2008; 8:915-928.

11. Samani AA, Yakar S, LeRoith D, Brodt P. The role of the IGF system in cancer growth and metastasis: overview and recent insights. Endocr Rev. 2007; 28:20-47.

12. Pollak M, Beamer W, Zhang JC. Insulin-like growth factors and prostate cancer. Cancer Metastasis Rev. 1998; 17:383-390.

13. Gu F, Schumacher FR, Canzian F, Allen NE, Albanes D, Berg CD, Berndt SI, Boeing H, Bueno-de-Mesquita HB, Buring JE, Chabbert-Buffet N, Chanock SJ, ClavelChapelon F, Dumeaux V, Gaziano JM, Giovannucci EL, et al. Eighteen insulin-like growth factor pathway genes, circulating levels of IGF-I and its binding protein, and risk of prostate and breast cancer. Cancer Epidemiol Biomarkers Prev. 2010; 19:2877-2887.

14. Rowlands MA, Gunnell D, Harris R, Vatten LJ, Holly JM, Martin RM. Circulating insulin-like growth factor peptides and prostate cancer risk: a systematic review and metaanalysis. Int J Cancer. 2009; 124:2416-2429.

15. Schumacher FR, Cheng I, Freedman ML, Mucci L, Allen NE, Pollak MN, Hayes RB, Stram DO, Canzian F, Henderson BE, Hunter DJ, Virtamo J, Manjer J, Gaziano JM, Kolonel LN, Tjonneland A, et al. A comprehensive analysis of common IGF1, IGFBP1 and IGFBP3 genetic variation with prospective IGF-I and IGFBP-3 blood levels and prostate cancer risk among Caucasians. Hum Mol Genet. 2010; 19:3089-3101.

16. Liao Y, Abel U, Grobholz R, Hermani A, Trojan L, Angel P, Mayer D. Up-regulation of insulin-like growth factor axis components in human primary prostate cancer correlates with tumor grade. Hum Pathol. 2005; 36:1186-1196.

17. Schayek H, Bentov I, Sun S, Plymate SR, Werner H. Progression to metastatic stage in a cellular model of prostate cancer is associated with methylation of the androgen receptor gene and transcriptional suppression of the insulin-like growth factor-I receptor gene. Exp Cell Res. 2010; 316:1479-1488.

18. Sutherland BW, Knoblaugh SE, Kaplan-Lefko PJ, Wang F, Holzenberger M, Greenberg NM. Conditional deletion of insulin-like growth factor-I receptor in prostate epithelium. Cancer Res. 2008; 68:3495-3504.

19. Ozkan EE. Plasma and tissue insulin-like growth factor-I receptor (IGF-IR) as a prognostic marker for prostate cancer and anti-IGF-IR agents as novel therapeutic strategy for refractory cases: a review. Mol Cell Endocrinol. 2011; 344:1-24.

20. $\mathrm{Zu} \mathrm{K}$, Martin NE, Fiorentino M, Flavin R, Lis RT, Sinnott JA, Finn S, Penney KL, Ma J, Fazli L, Gleave ME, Bismar TA, Stampfer MJ, Pollak MN, Loda M, Mucci LA, et al. Protein expression of PTEN, insulin-like growth factor I receptor (IGF-IR), and lethal prostate cancer: a prospective study. Cancer Epidemiol Biomarkers Prev. 2013; 22:1984-1993.

21. Chi KN, Gleave ME, Fazli L, Goldenberg SL, So A, Kollmannsberger C, Murray N, Tinker A, Pollak M. A phase II pharmacodynamic study of preoperative figitumumab in patients with localized prostate cancer. Clin Cancer Res. 2012; 18:3407-3413.

22. Dean JP, Sprenger CC, Wan J, Haugk K, Ellis WJ, Lin DW, Corman JM, Dalkin BL, Mostaghel E, Nelson PS, Cohen P, Montgomery B, Plymate SR. Response of the insulinlike growth factor (IGF) system to IGF-IR inhibition and androgen deprivation in a neoadjuvant prostate cancer trial: effects of obesity and androgen deprivation. J Clin Endocrinol Metab. 2013; 98:E820-828.

23. Garcia-Echeverria C, Pearson MA, Marti A, Meyer T, Mestan J, Zimmermann J, Gao J, Brueggen J, Capraro HG, Cozens R, Evans DB, Fabbro D, Furet P, Porta DG, Liebetanz J, Martiny-Baron G, et al. In vivo antitumor activity of NVP-AEW41-A novel, potent, and selective inhibitor of the IGF-IR kinase. Cancer Cell. 2004; 5:231-239.

24. Scotlandi K, Manara MC, Nicoletti G, Lollini PL, Lukas S, Benini S, Croci S, Perdichizzi S, Zambelli D, Serra M, Garcia-Echeverria C, Hofmann F, Picci P. Antitumor activity of the insulin-like growth factor-I receptor kinase inhibitor NVP-AEW541 in musculoskeletal tumors. Cancer Res. 2005; 65:3868-3876.

25. Garofalo C, Manara MC, Nicoletti G, Marino MT, Lollini PL, Astolfi A, Pandini G, Lopez-Guerrero JA, Schaefer KL, Belfiore A, Picci P, Scotlandi K. Efficacy of and resistance to anti-IGF-1R therapies in Ewing's sarcoma is dependent on insulin receptor signaling. Oncogene. 2011; 30:2730-2740.

26. Garofalo C, Mancarella C, Grilli A, Manara MC, Astolfi A, Marino MT, Conte A, Sigismund S, Care A, Belfiore A, Picci P, Scotlandi K. Identification of common and distinctive mechanisms of resistance to different anti-IGFIR agents in Ewing's sarcoma. Mol Endocrinol. 2012; 26:1603-1616.

27. Molife LR, Fong PC, Paccagnella L, Reid AH, Shaw HM, Vidal L, Arkenau HT, Karavasilis V, Yap TA, Olmos D, Spicer J, Postel-Vinay S, Yin D, Lipton A, Demers L, Leitzel K, et al. The insulin-like growth factor-I receptor inhibitor figitumumab (CP-751, 871) in combination with docetaxel in patients with advanced solid tumours: results of a phase Ib dose-escalation, open-label study. Br J Cancer. 2010; 103:332-339.

28. Kumar-Sinha C, Tomlins SA, Chinnaiyan AM. Recurrent gene fusions in prostate cancer. Nat Rev Cancer. 2008; $8: 497-511$. 
29. Cai C, Wang H, Xu Y, Chen S, Balk SP. Reactivation of androgen receptor-regulated TMPRSS2:ERG gene expression in castration-resistant prostate cancer. Cancer Res. 2009; 69:6027-6032.

30. Werner H, Sarfstein R. Transcriptional and epigenetic control of IGF1R gene expression: implications in metabolism and cancer. Growth Horm IGF Res. 2014; 24:112-118.

31. Toretsky JA, Kalebic T, Blakesley V, LeRoith D, Helman LJ. The insulin-like growth factor-I receptor is required for EWS/FLI-1 transformation of fibroblasts. J Biol Chem. 1997; 272:30822-30827.

32. Werner H, Idelman G, Rubinstein M, Pattee P, Nagalla SR, Roberts CT Jr. A novel EWS-WT1 gene fusion product in desmoplastic small round cell tumor is a potent transactivator of the insulin-like growth factor-I receptor (IGF-IR) gene. Cancer Lett. 2007; 247:84-90.

33. Aggarwal RR, Ryan CJ, Chan JM. Insulin-like growth factor pathway: a link between androgen deprivation therapy (ADT), insulin resistance, and disease progression in patients with prostate cancer? Urol Oncol. 2013; 31:522-530.

34. Brenner JC, Ateeq B, Li Y, Yocum AK, Cao Q, Asangani IA, Patel S, Wang $\mathrm{X}$, Liang $\mathrm{H}$, Yu J, Palanisamy N, Siddiqui J, Yan W, Cao X, Mehra R, Sabolch A, et al. Mechanistic rationale for inhibition of poly(ADP-ribose) polymerase in ETS gene fusion-positive prostate cancer. Cancer Cell. 2011; 19:664-678.

35. de Bono JS, Attard G, Adjei A, Pollak MN, Fong PC, Haluska P, Roberts L, Melvin C, Repollet M, Chianese D, Connely M, Terstappen LW, Gualberto A. Potential applications for circulating tumor cells expressing the insulinlike growth factor-I receptor. Clin Cancer Res. 2007; 13:3611-3616.

36. Attard G, Reid AH, Olmos D, de Bono JS. Antitumor activity with CYP17 blockade indicates that castration-resistant prostate cancer frequently remains hormone driven. Cancer Res. 2009; 69:4937-4940.

37. Cai H, Babic I, Wei X, Huang J, Witte ON. Invasive prostate carcinoma driven by c-Src and androgen receptor synergy. Cancer Res. 2011; 71:862-872.

38. Carver BS, Chapinski C, Wongvipat J, Hieronymus H, Chen Y, Chandarlapaty S, Arora VK, Le C, Koutcher J, Scher H, Scardino PT, Rosen N, Sawyers CL. Reciprocal feedback regulation of PI3K and androgen receptor signaling in PTEN-deficient prostate cancer. Cancer Cell. 2011; 19:575-586.

39. Magistroni V, Mologni L, Sanselicio S, Reid JF, Redaelli S, Piazza R, Viltadi M, Bovo G, Strada G, Grasso M, Gariboldi M, Gambacorti-Passerini C. ERG deregulation induces PIM1 over-expression and aneuploidy in prostate epithelial cells. PLoS One. 2011; 6:e28162.

40. Fernandez-Serra A, Rubio L, Calatrava A, Rubio-Briones J, Salgado R, Gil-Benso R, Espinet B, Garcia-Casado Z, Lopez-Guerrero JA. Molecular characterization and clinical impact of TMPRSS2-ERG rearrangement on prostate cancer: comparison between FISH and RT-PCR. Biomed Res Int. 2013; 2013:465179.

41. Livak KJ, Schmittgen TD. Analysis of relative gene expression data using real-time quantitative PCR and the 2(-Delta Delta C(T)) Method. Methods. 2001; 25:402-408.

42. Malaguarnera R, Frasca F, Garozzo A, Giani F, Pandini G, Vella V, Vigneri R, Belfiore A. Insulin receptor isoforms and insulin-like growth factor receptor in human follicular cell precursors from papillary thyroid cancer and normal thyroid. J Clin Endocrinol Metab. 2011; 96:766-774.

43. Rocchi A, Manara MC, Sciandra M, Zambelli D, Nardi F, Nicoletti G, Garofalo C, Meschini S, Astolfi A, Colombo MP, Lessnick SL, Picci P, Scotlandi K. CD99 inhibits neural differentiation of human Ewing sarcoma cells and thereby contributes to oncogenesis. J Clin Invest. 2010; 120:668-680.

44. Di Giandomenico S, Frapolli R, Bello E, Uboldi S, Licandro SA, Marchini S, Beltrame L, Brich S, Mauro V, Tamborini E, Pilotti S, Casali PG, Grosso F, Sanfilippo R, Gronchi A, Mantovani R, et al. Mode of action of trabectedin in myxoid liposarcomas. Oncogene. 2014; 33:5201-10.

45. Frank SR, Schroeder M, Fernandez P, Taubert S, Amati B. Binding of c-Myc to chromatin mediates mitogen-induced acetylation of histone H4 and gene activation. Genes Dev. 2001; 15:2069-2082.

46. Chou TC, Motzer RJ, Tong Y, Bosl GJ. Computerized quantitation of synergism and antagonism of taxol, topotecan, and cisplatin against human teratocarcinoma cell growth: a rational approach to clinical protocol design. J Natl Cancer Inst. 1994; 86:1517-1524. 